\title{
Bio-based thermoset composites from epoxidised linseed oil and expanded starch $\uparrow$
}

\author{
Nontipa Supanchaiyamat, ${ }^{\text {ab }}$ Andrew J. Hunt, ${ }^{a}$ Peter S. Shuttleworth, ${ }^{c}$ Cheng Ding, ${ }^{a}$ \\ James H. Clark ${ }^{a}$ and Avtar S. Matharu ${ }^{a}$
}

Bio-based thermoset composites comprising epoxidised linseed oil (ELO), a bio-derived diacid crosslinker (Pripol 1009) and starch are reported. High amylose corn starch in its native, gelatinised and retrograded forms were used in the formulation to yield water resistant films with good thermal stability. The textural properties of gelatinised and retrograded starches were characterised using scanning electron microscopy and porosimetry and their thermal stability was determined using thermogravimetric analysis. The inclusion of $20 \%$ gelatinised starch significantly improved the mechanical properties of the bio-based thermoset composite with tensile strength being enhanced by $227 \%$ and Young's modulus by $166 \%$ with respect to the starch-free counterparts. Unlike in formulations comprising native starch, no visible phase separation was noticed for gelatinised- or retrograded-starch thermosets. Thermal analysis and gel time study revealed retardation of the cure process in the presence of starch. However, the presence of hydroxyl groups within the starch was likely to promote a more extensive curing process, as indicated by the higher total enthalpy of reaction obtained. This was supported by thermal stability studies, which indicated a greater proportion of crosslinked material obtained in films with higher starch content.

Received 26th March 2014

Accepted 14th May 2014

DOI: $10.1039 / c 4 r a 03935 a$

www.rsc.org/advances

\section{Introduction}

Plant oils are considered one of the most promising renewable resources for (bio)polymers, owing to their abundance, inherent biodegradability and versatility. Ronda et al. ${ }^{1}$ report three routes for the transformation of plant oils to polymers. The first route concerns the direct polymerisation of the triglyceride via the inherent double bonds. The second route involves the introduction of readily polymerisable functionalities through the unsaturation of the triglycerides. The third route is to use plant oil-derived chemicals to produce monomers for the polymer manufacture. For example, linseed oil (LO) is obtained from flax seeds, which are traditionally ground into a fine powder and pressed to extract the oil. ${ }^{2}$ LO mainly comprises highly unsaturated triglycerides, rich in linolenic acid (C18:3), linoleic acid (C18:2) and oleic acid (C18:1). ${ }^{3}$ LO finds its use in paints as it forms a thin film after being spread, due to the auto-oxidation of the double bonds on exposure to air. ${ }^{4,5}$ However, the direct polymerisation of unmodified plant oils is generally considered

${ }^{a}$ Department of Chemistry, The University of York, Heslington, York, YO10 5DD, UK. E-mail: nontipa.s@gmail.com; Fax: +44 (0)1904 322705; Tel: +44 (0)1904 322546

${ }^{b}$ Materials Research Unit, Department of Chemistry, Faculty of Science, Khon Kaen University, Khon Kaen, 40002, Thailand

${ }^{c}$ Departamento de Física de Polimeros, Elastómeros y Aplicaciones Energéticas, Instituto de Ciencia y Tecnología de Polimeros, CSIC, Madrid, Spain

$\dagger$ Electronic supplementary information (ESI) available. See DOI: 10.1039/c4ra03935a difficult. Therefore, various reactions can be performed on the double bonds in order to introduce readily polymerisable functionalities. The modifications include epoxidation, hydroformylation and metathesis. Epoxidised linseed oil (ELO) is commercially available and commonly used as plasticiser and stabiliser in polyvinyl chloride (PVC), coatings and adhesives. ${ }^{6}$ In flooring applications, linseed oil (or oxidised linseed oil) is utilised in linoleum. ${ }^{7}$ Epoxidised oils can not only be used as precursors for epoxy resins but also for the preparation of polyols for polyurethane (PU) production. ${ }^{8}$ Epoxidised soybean oil has been used in combination with acrylic acid to produce acrylated epoxidised soybean oil, which is extensively used in polymers and composites. ${ }^{9}$ The preparation of fatty acid-derived diisocyanate to produce bio-based PU has recently been reported and it was found to exhibit comparable properties compared to its petroleum-derived counterpart..$^{10}$

Thermosetting resins are highly-crosslinked polymers that are cured by heat, pressure, light radiation or a combination of these energy sources. ${ }^{11}$ Thermosetting resins from epoxidised plant oils, such as epoxidised soybean oil (ESBO) and epoxidised castor oil (ECO), have been studied using photoinitiators as curing agents. Epoxidised plant oils are on numerous occasions combined with acid anhydride crosslinkers, in particular, maleic anhydride and unsubstituted- and substituted-phthalic anhydrides. ${ }^{12-14}$ The primary source of these crosslinking agents is largely from petroleum-based feedstock. ${ }^{12,13,15}$ The use of a bio-derived crosslinker in the presence of amine catalysts in 
order to produce a bio-based thermosetting resin has recently been reported. ${ }^{16}$ In addition, fibres and/or particles have been extensively used as reinforcement fillers for plant oil based resins thus enhancing mechanical properties. ${ }^{17-19}$

The use of starch in the production of composites has been increasingly investigated during the last few decades, due to its unique properties and biodegradability. Starch is a naturally occurring polysaccharide, abundantly available, relatively inexpensive and can be sourced from waste product. ${ }^{20}$ Starch has been used as a filler for hydrophobic polymers, such as polyethylene to yield a partially biodegradable polymer and has also been blended with degradable polymers such as polyvinyl alcohol (PVA) and polycaprolactone (PCL). ${ }^{21,22}$ The addition of PVA to a starch matrix demonstrated improved tensile strength and elongation. ${ }^{23}$ Nonetheless, similar to starch, the fact that PVA is also moisture-sensitive, has limited starch/PVA blends for many applications. Averous et al. studied the combination of PCL with thermoplastic starch and found that, despite phase separation of the blend, the dimensional stability and hydrophobicity improved significantly compared to those of native thermoplastic starch (TPS) alone. ${ }^{24}$ Interestingly, PCL/high amylose corn starch blend gave better mechanical properties than other starch-types owing to its small granular size allowing good dispersion in the PCL matrix. ${ }^{25}$

In our previous report, ELO and bio-derived dimerised acid (Pripol 1009) were used to produce bio-based thermosetting films. Different amine catalysts were added to the reaction mixture and the formulation using 4-N,N-dimethylaminopyridine (DMAP) yielded films with the most promising physical properties. ${ }^{16}$ Herein, native and modified starches (expansion of starch via gelatinisation and retrogradation) were incorporated into the same formulation in order to study the effect of these starches with respect to the thermal, gelation and mechanical properties of the resultant films.

\section{Experimental}

\section{Materials}

ELO was obtained from Akcros Chemicals as Lankroflex L (oxirane oxygen $=9 \%$ ). Pripol 1009 bio-derived diacid was kindly supplied by Croda and 4- $N, N$-dimethylaminopyridine (DMAP) was purchased from Fluka. Toluene and ethanol were obtained from Fisher Scientific and were used without further purification.

\section{Preparation of gelatinised starch}

Gelatinised starch was prepared by heating $\left(120{ }^{\circ} \mathrm{C}, 2 \mathrm{~h}\right)$, with continuous stirring, a $10 \mathrm{wt} \%$ (dry basis) slurry of high amylose corn starch in water contained within a glass pressure bottle. The resultant clear gel was cooled to room temperature prior to the addition of an equivolume of ethanol. The mixture was stirred vigorously at room temperature for 10 minutes, centrifuged (3500 rpm, 10 minutes) and the supernatant was decanted and discarded. Ethanol was added to the starch pellet and this solvent exchange process was repeated four times with ethanol before placing the material within a vacuum oven set at $50{ }^{\circ} \mathrm{C}$ overnight to afford the desired gelatinised starch. ${ }^{26}$

\section{Preparation of retrograded starch}

The gelatinised starch (prior to the solvent exchange) was placed in a refrigerator at $5{ }^{\circ} \mathrm{C}$ for 4 days. The retrograded starch subsequently underwent the solvent exchange and drying process as described previously for the gelatinised starch.

\section{BET surface area measurement}

Nitrogen adsorption/desorption isotherms were conducted using a Micromeritics ASAP 2010 volumetric adsorption analyser at $-196{ }^{\circ} \mathrm{C}$. Prior to analysis, the samples were degassed at $65{ }^{\circ} \mathrm{C}$ for at least $3 \mathrm{~h}$ under reduced pressure and mass differences were corrected after the experiment. The surface area of samples was automatically calculated by the Micromeritics ASAP 2010 volumetric adsorption analyser. The isotherm data were subjected to the BET method to obtain the BET specific surface area data $\left(S_{\mathrm{BET}}\right){ }^{27}$

\section{Film preparation}

A vigorously stirred mixture of ELO (3.5 g) and native or expanded starch suspended in toluene (dry weight $=0.8,1.75$ and $2.1 \mathrm{~g}$ for $10 \%, 20 \%$ and $23 \%$ starch, respectively) to aid dispersion, was heated to $120{ }^{\circ} \mathrm{C}$ until constant weight was achieved. Subsequently, Pripol 1009 (3.5 g) and DMAP (0.5\% by weight of the total resin weight) were added and the mixture was maintained at $120{ }^{\circ} \mathrm{C}$ for a further 3 minutes, poured into a circular aluminium tray (inner diameter $=70 \mathrm{~mm}$ ) and cured in an oven at $140{ }^{\circ} \mathrm{C}$ for $2 \mathrm{~h}$.

\section{Scanning electron microscopy}

Film samples were cut into small pieces $(2 \times 10 \mathrm{~mm})$, which were mounted on alumina sample holders using double-sided tape. The samples were positioned so that the cross-section of the films can be seen on the top view. Prior to analysis, an approximate $5 \mathrm{~nm} \mathrm{Au} / \mathrm{Pd}$ coating was applied to the samples using a high-resolution sputter SC-7640 coating device at a sputtering rate of $1500 \mathrm{~V} \mathrm{~min}^{-1}$. The samples were viewed using a JEOL JSM-6490LV (JEOL, Japan).

\section{Mechanical test}

The resulting films were cut into standard dumb-bell shapes $(60 \times 10 \mathrm{~mm})$ with film thickness in the region of 1-1.5 mm. Tensile studies were conducted in triplicate using an Instron 3367 universal testing machine fitted with $1000 \mathrm{~N}$ capacity load cell. The initial grip separation was set at $35 \mathrm{~mm}$ and the crosshead speed was $20 \mathrm{~mm} \mathrm{~min}^{-1}$.

\section{Water uptake}

The water uptake was measured in accordance to the method developed by Supanchaiyamat et al. ${ }^{16}$

\section{Thermal degradation temperature}

The degradation temperature was determined using a Stanton Redcroft STA 625 (TG/DSC). Starch samples were heated from 25-500 ${ }^{\circ} \mathrm{C}$, whilst film samples were heated from $25-625{ }^{\circ} \mathrm{C}$, 
both at $10{ }^{\circ} \mathrm{C} \min ^{-1}$ under a nitrogen atmosphere. The initial sample weight was in the region of $10-15 \mathrm{mg}$.

\section{Infrared spectroscopy}

In order to follow the curing reaction for each formulation, a Bruker Vertex 70 spectrophotometer was used in Attenuated Total Reflectance (ATR) mode, using a resolution of $2 \mathrm{~cm}^{-1}$ and 32 scans. All spectra were normalised using OPUS software as provided by the instrument manufacturer.

All components in the formulation were pre-mixed using a high speed overhead stirrer in a glass vessel $\left(20^{\circ} \mathrm{C}\right)$, their initial spectrum recorded ( $t=0 \mathrm{~s}$ ) and then cured in an aluminium tray at $140{ }^{\circ} \mathrm{C}$ with spectra recorded every 30 minutes for 90 minutes.

\section{MDSC of the reaction mixtures}

Reaction mixtures were investigated using a TA Q2000 modulated differential scanning calorimeter (MDSC). The mixtures were accurately weighed (10 $\mathrm{mg})$ into high-pressure stainless steel pans, sealed and subjected to a heat/cool cycle from -80 ${ }^{\circ} \mathrm{C}$ to $250{ }^{\circ} \mathrm{C}$ at $1{ }^{\circ} \mathrm{C} \mathrm{min}^{-1}$ with a modulation cycle of $\pm 0.5{ }^{\circ} \mathrm{C}$ every 200 seconds.

\section{Viscosity measurement}

The viscosity of the mixtures was studied using a Brookfield R/SCPS plus rheometer. The gap between the cone and the plate was set at $0.5 \mathrm{~mm}$ with steady shear rate at $30 \mathrm{~s}^{-1}$. Isothermal measurements were performed at $140{ }^{\circ} \mathrm{C}$ until the extent of the reaction reached the limit of the instrument. The gel point was defined as the point at which the diverging steady state viscosity becomes infinite. ${ }^{28,29}$

\section{Results and discussion}

\section{Characterisation of modified starches}

The process of gelatinisation and retrogradation was used to open up the granular structure of starch and to increase its surface area, i.e. expansion. SEM analysis showed that textural changes of the granule surfaces had taken place after the modification process (ESI, Fig. S1†). Prior to the modification, the surface of the granules was smooth without obvious pores or fissures. After gelatinisation and retrogradation, the starch granules showed porous texture. Porosity was evidenced by nitrogen adsorption porosimetry in terms of surface area (Table 1). Native starch granules possess a low surface area $\left(<1 \mathrm{~m}^{2} \mathrm{~g}^{-1}\right)$ whilst gelatinised and retrograded starch process significantly increased surface areas, $110 \mathrm{~m}^{2} \mathrm{~g}^{-1}$ and $154 \mathrm{~m}^{2} \mathrm{~g}^{-1}$, respectively.

These enhanced textural characteristics of the porous starch enables improved contact between the granules and the polymer matrix. The change in surface roughness of the materials may also improve wetting. Moreover, the open structure of expanded starch and gain in accessibility to the hydroxyl groups facilitates high degrees of chemical modification. ${ }^{26,30}$ In this work, this could possibly enable chemical interaction between the starch filler and ELO and/or Pripol in the film formulation
Table 1 Surface area of native, gelatinised starch (GS) and retrograded starch (RS)

\begin{tabular}{ll}
\hline Starch & BET surface area $\left(\mathrm{m}^{2} \mathrm{~g}^{-1}\right)$ \\
\hline Native starch & $<1$ \\
GS & 110 \\
RS & 154
\end{tabular}

and consequently improve the mechanical properties of the product. This postulation was investigated further in the study of the curing reaction of the thermoset as discussed later.

\section{Thermal decomposition of starch and modified starches}

TGA traces of all starch samples showed two significant weight loss events (ESI, Fig. S2 and Table S1† and respective text regarding the decomposition process.). The first occurred almost immediately after the samples were heated and finished at around $100{ }^{\circ} \mathrm{C}$. This corresponded to the evaporation of water or other volatile components such as traces of the exchanging solvents, representing approximately $10 \%$ of the total sample weight. There was little or no mass loss in the region of 150$230{ }^{\circ} \mathrm{C}$. The second weight loss appeared between approximately 260 and $330{ }^{\circ} \mathrm{C}$ and represented the thermal decomposition of the material. ${ }^{31,32}$

\section{Mechanical properties of the composites}

Effect of starch type. Native high amylose corn starch (unmodified), gelatinised starch or retrograded starch was added to the standard formulation of ELO and Pripol 1009 using DMAP as catalyst. The amount of starch used in the formulation was set at $10 \mathrm{wt} \%$. The tensile data showed that incorporation of gelatinised starch moderately improved the mechanical properties of the produced film with a respective increase of $47 \%, 11 \%$ and $3 \%$, for tensile strength, Young's modulus and elongation at break (Fig. 1A). Incorporation of retrograded starch yielded a slight increase in tensile strength (approximately 6\%) compared to the native starch but the Young's modulus and elongation at break decreased by $4 \%$ and $9 \%$, respectively. According to the results obtained, the type of starch has minimal effect on the mechanical properties of the films.

Effect of starch concentration. Various amounts of gelatinised starch were added to the standard mixture in order to investigate the influence of starch concentration on the mechanical properties of the resulting films (Fig. 1B). The addition of gelatinised starch (20 wt\%) clearly improved both the tensile strength and Young's modulus of the films, with enhancements of $227 \%$ and $166 \%$, respectively. At low starch concentrations (10 wt $\%$ ), the elongation at break was scarcely affected. However, at the higher starch loadings, the elongations at break decreased by $12 \%$ with $20 \mathrm{wt} \%$ of starch, and a considerable decrease was observed (47\%) with loadings of $23 \mathrm{wt} \%$ starch. It is known that the addition of fillers typically 

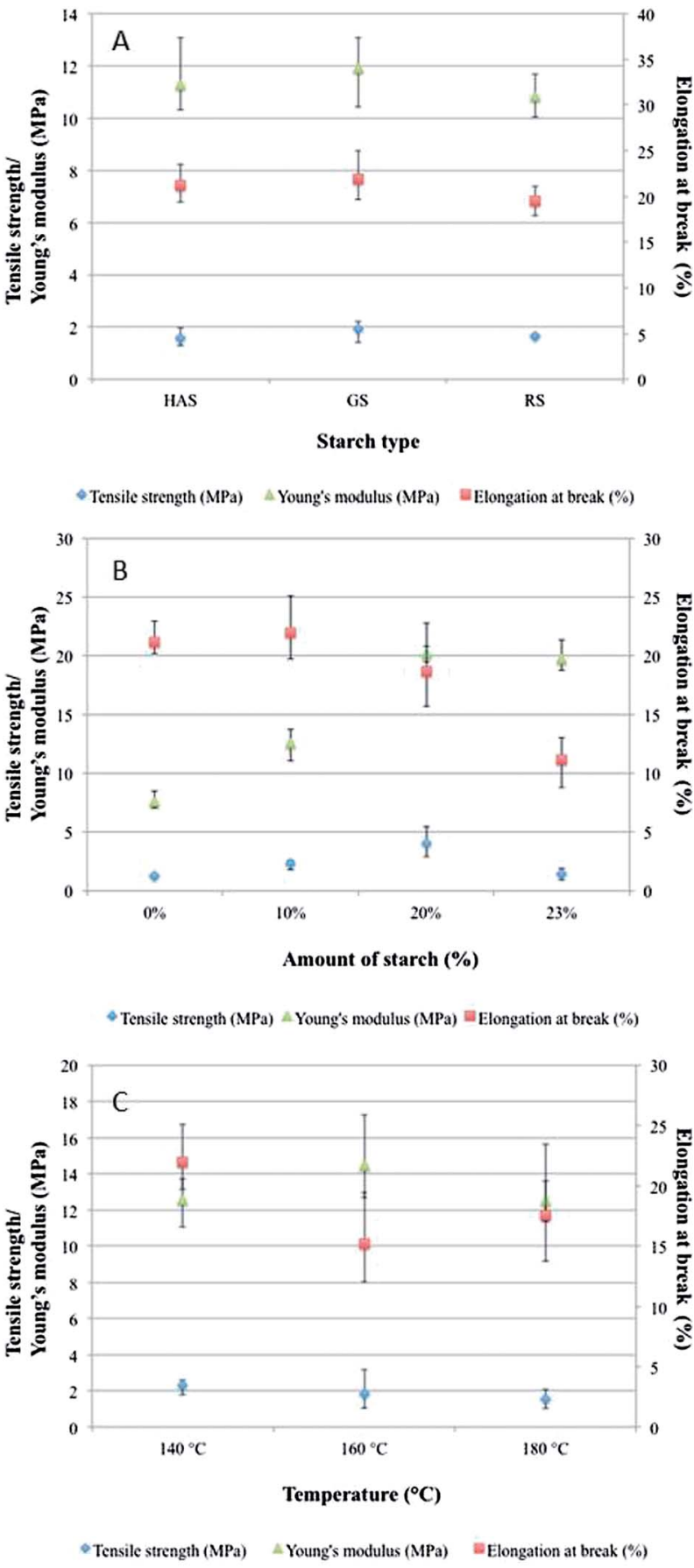

Fig. 1 (A) Effect of starch type on the mechanical properties of films high amylose corn starch (HAS), gelatinised starch (GS) and retrograded starch (RS), (B) effect of gelatinised starch concentration (wt\%) on the mechanical properties of films and (C) effect of curing temperature on the mechanical properties of films.

decreases the elongation at break of certain composites even at very low loadings. ${ }^{33,34}$

Increasing the amount of starch filler gives rise to the decline of elongation at break of the materials. This deterioration may be attributed to the difference in polar characteristics of starch and the polymer matrix, which induced poor interfacial

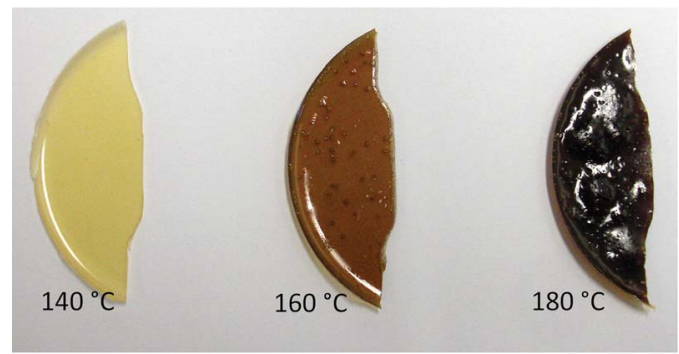

Fig. 2 Films made of ELO, Pripol 1009, gelatinised starch and DMAP cured at various temperatures.

adhesion between the two components. ${ }^{35}$ It was also noted that the maximum amount of starch that could be incorporated within the formulation was $23 \mathrm{wt} \%$, as greater proportions led to a material that could not be cast as a film.

Effect of curing temperature. Hill et al. studied the reactivity of etherified melamine-formaldehyde resins with polyol binders at various curing temperatures, which was found to influence the mechanical properties of the product. ${ }^{36}$ As such three different curing temperatures were investigated using the formulation, which was comprised of ELO, Pripol 1009 and 10\% wt of gelatinised starch in the presence of DMAP, in order to optimise the film production process. The resulting data is illustrated in Fig. 1C.

The highest tensile strength was obtained when the film was cured at $140{ }^{\circ} \mathrm{C}$, at which the resulting film showed $23 \%$ and $50 \%$ enhancement compared to those cured at $160{ }^{\circ} \mathrm{C}$ and $180^{\circ} \mathrm{C}$, respectively. The highest Young's modulus was achieved curing at a temperature of $160{ }^{\circ} \mathrm{C}$, however, a $31 \%$ drop in elongation at break was observed compared to the film prepared at $140{ }^{\circ} \mathrm{C}$. The film cured at $180{ }^{\circ} \mathrm{C}$ had the poorest performance characteristics of the three curing temperatures. Moreover, higher curing temperatures resulted in significant darkening of the films as shown in Fig. 2. Dell'Erba et al. also observed darkening of epoxy resins using DMAP as catalyst and explained that the colouration was due to the segments of the polymerised chains that have the initiator with conjugated double bonds attached to one of the chain ends. ${ }^{37}$ Therefore, overall the optimal curing temperature was found to be at $140{ }^{\circ} \mathrm{C}$, yielding the best quality (visual) films.

\section{Morphological study of the composites}

The cross-section of starch composite films were observed using SEM. It can be seen that phase separation occurred with the films containing native starch (Fig. 3A). The enlarged images show that one side of the film (Fig. 3B) contains a greater proportion of the starch granules than the other (Fig. 3C).

The cross-section of films with gelatinised and retrograded starches revealed no noticeable phase separation (Fig. 4A). The starch granules appear to be equally distributed throughout the film (Fig. 4B and C) suggesting better dispersion in the polymer matrix compared with native granules. This may be tentatively due to the enhanced porosity associated with expansion of the granules allowing the polymer to penetrate into the starch matrix and consequently enabled a uniform dispersion. It was 


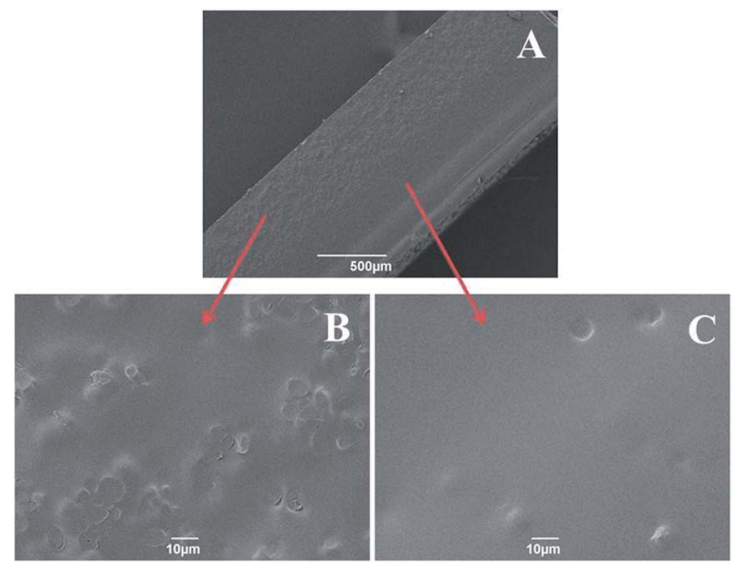

Fig. 3 Scanning electron micrographs (magnification $\times 50$ and $\times 1000$ ) of the cross-section of (A) the film with native high amylose corn starch, (B) back of the film and (C) front of the film.

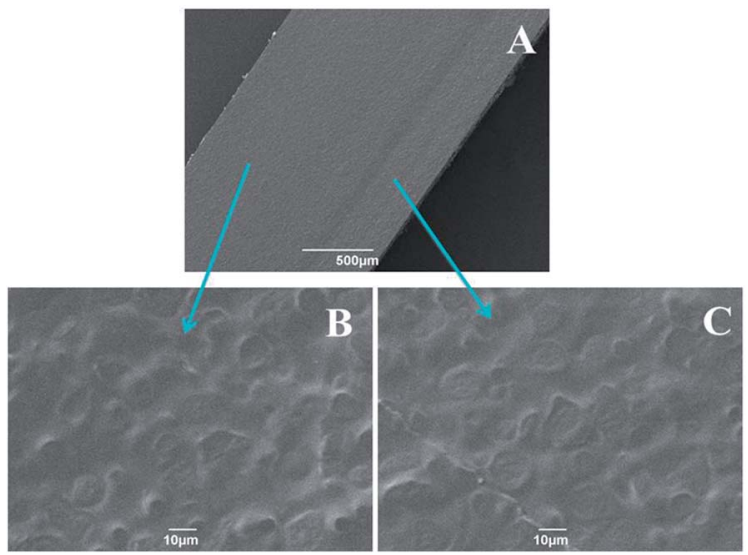

Fig. 4 Scanning electron micrographs (magnification $\times 50$ and $\times 1000)$ of the cross-section of film with gelatinised starch $-(A)$ whole film, (B) back of the film and (C) front of the film.

also noted that the size of starch remained in the region of 5$10 \mu \mathrm{m}$, which indicated that no swelling had occurred during the cure.

\section{Water uptake}

The average water uptake of the films with starch was between 2 and $3 \%$ (Fig. 5A). The film with native starch absorbed slightly more water compared to the modified ones. As shown in the morphological study, the films with gelatinised and retrograded starches were uniformly dispersed, indicating good interfacial adhesion between the filler and polymer matrix, leading to better resin coverage of the granules and reduced water uptake. ${ }^{38}$ Varying the starch loadings in the composites demonstrated that the water uptake increased with the proportion of starch added to the resin (Fig. 5B). The film without starch after $24 \mathrm{~h}$ immersion in water absorbed less than $0.5 \mathrm{wt} \%$, whilst the water uptake of the film with $20 \mathrm{wt} \%$ gelatinised starch rose to nearly $4 \%$. By increasing the starch loading from $20 \mathrm{wt} \%$ to $23 \mathrm{wt} \%$, the difference of water uptake
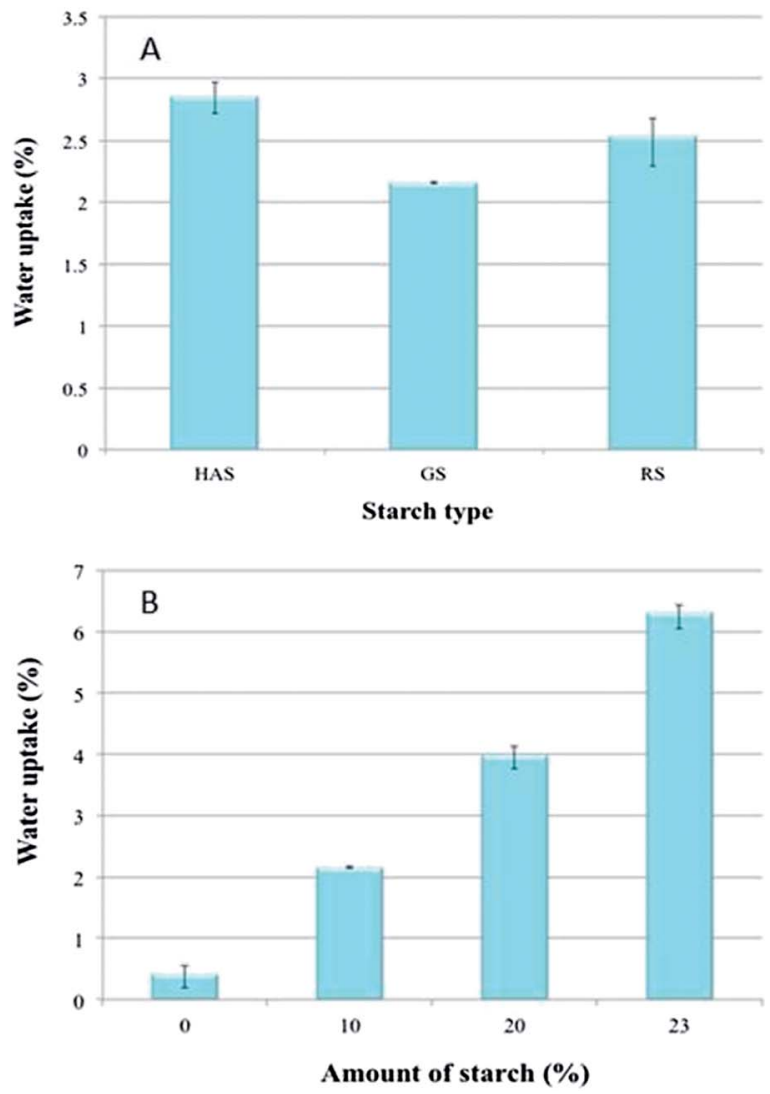

Fig. 5 (A) Effect of different types of starch on water uptake of the films - high amylose corn starch (HAS), gelatinised starch (GS) and retrograded starch (RS) and (B) Effect of starch loadings on water uptake of the films.

of the films became notably significant. The higher content of starch may have led to filler agglomeration and decreased resin coverage, which would result in the $58 \%$ increase in water content compared to the film prepared with $20 \mathrm{wt} \%$ gelatinised starch loadings. ${ }^{38}$ The water uptake of the films could be potentially reduced by using chemically modified starches that are more hydrophobic, such as acetylated starch. ${ }^{39}$

\section{Mechanistic study of the system}

The mechanism of reaction between epoxide and carboxyl moieties has been widely investigated but not yet fully elucidated. For example, Shechter and Wynstra proposed the following four types of reactions that might occur on reacting a carboxylic acid with a glycidyl ether: ${ }^{40}$

(a) epoxide + acid $\rightarrow$ monoester (addition esterification);

(b) epoxide + monoester $\rightarrow$ ether (etherification);

(c) acid + monoester $\rightarrow$ diester + water (condensation esterification), and;

(d) epoxide + water $\rightarrow$ glycol (hydrolysis).

However, Matějka et al. who studied the base-catalysed reactions of a model system of phenylglycidyl ether and caproic acid proposed that reactions (b), (c) and (d) did not happen or had no significant contribution depending on catalyst types and the molar ratio of acid/epoxy group. ${ }^{41}$ Madec et al. summarised 
the kinetics and mechanisms of polyesterification reactions between carboxylic acids and diepoxides proposing that amines could either act as a base to react with the acid first or as an initiator (nucleophile) to open the epoxide group. ${ }^{42-44}$ Both mechanisms are competitive depending on the basicity or nucleophilicity of the amine, solvent and temperature but the base mechanism, i.e., deprotonation of the carboxylic acid, was considered to be the primary reaction. DMAP has been reported to be an effective initiator of anionic ring-opening polymerisation of DGEBA ${ }^{45}$ and as an efficient catalyst in the reaction between DGEBA and carboxyl-functionalised organotriethoxysilane (see ESI section - Mechanistic study of the system and Fig. S3† within). ${ }^{46}$

\section{Thermal properties of the composites}

TGA thermograms of all samples revealed practically no weight loss up to $150{ }^{\circ} \mathrm{C}$. Between 150 and $250{ }^{\circ} \mathrm{C}$, a slight reduction in mass could be observed for the samples that contained starch (Fig. 6A). Although the resin without starch displayed a single significant weight loss starting around $350{ }^{\circ} \mathrm{C}$, the dTG curve of this material clearly showed that the resin experienced a twostage thermal decomposition (Fig. 6B). The first stage, which was the main thermal event, occurred in the temperature range of $380-420^{\circ} \mathrm{C}$ and the second stage took place between 440 and $460{ }^{\circ} \mathrm{C}$. The first stage of the decomposition could be partially
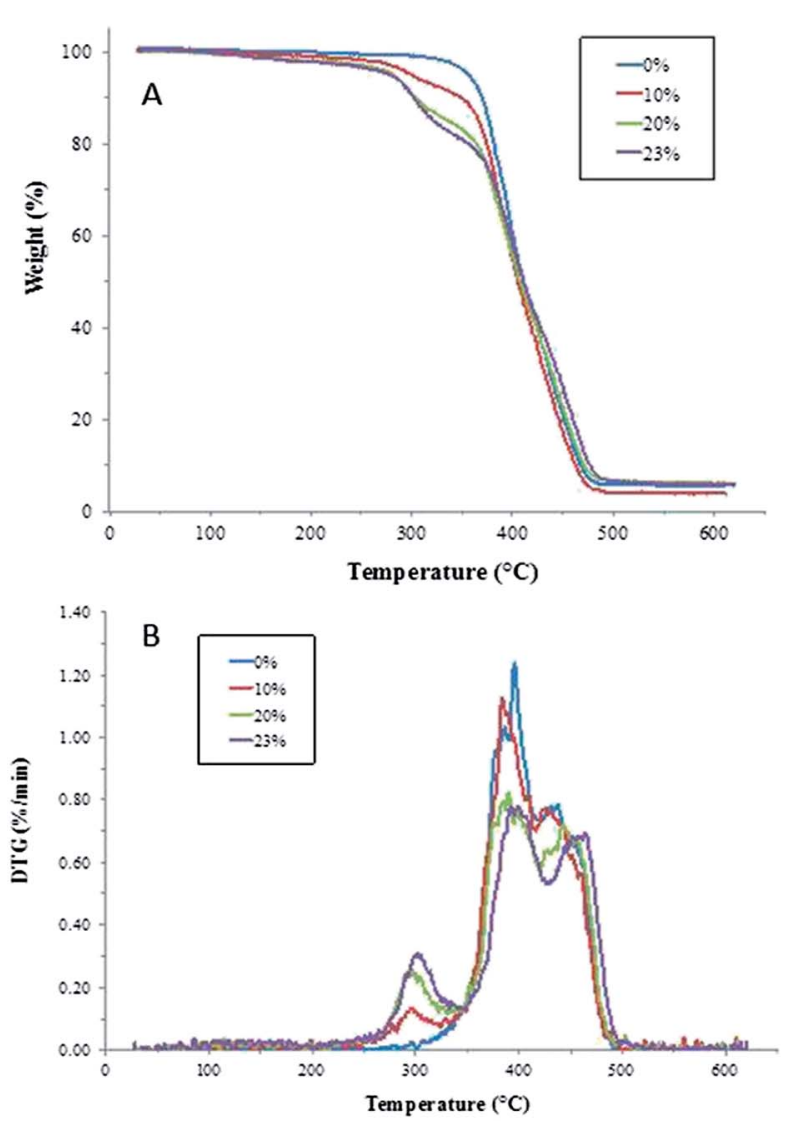

Fig. 6 (A) TGA thermograms of films with different amounts of added starch and (B) respective dTG curves. attributed to the unreacted ELO, which typically decomposes at $380{ }^{\circ} \mathrm{C}$ (ESI, Fig. S4 $\dagger$ ). A similar effect has been reported by Gerbase et al. in their study of epoxidised soybean oil based thermosets, which stated that unreacted components in the resin were responsible for the decomposition at lower temperature than that of the polymerised resin. ${ }^{13}$ The first stage decomposition, with a maximum rate at $405{ }^{\circ} \mathrm{C}$ was assigned mainly to the crosslinked polymer. The second stage of decomposition suggested that a proportion of the material may contain a greater level of crosslinking than other regions of the resin. Improved thermal stability with increased crosslinking has previously been reported for polystyrene beads by Li et al. ${ }^{\mathbf{4 7}}$

The starch-containing composites exhibited two major weight loss events as evidence by TGA (Fig. 6A). The first weight loss event commenced at approximately $280{ }^{\circ} \mathrm{C}$ and increased with starch content as also seen in the dTG curves (Fig. 6B). Therefore, this transition was assigned to the decomposition of starch within the composites. The second weight loss event began at around $350{ }^{\circ} \mathrm{C}$ and finished at $500{ }^{\circ} \mathrm{C}$, which was in the same region as decomposition observed for the resin without starch. The dTG curves of these starch-containing samples also showed two transitions during the decomposition. Interestingly, the ratio of the second stage to the first stage of decomposition became more significant as the amount of starch added increased. This may suggest that the presence of starch is potentially promoting additional crosslinking within the resin formulation hence an increase in the proportion of highly crosslinked material was observed.

\section{Thermal study of the curing reaction}

Modulated DSC was used to characterise thermal events during the curing process of the reaction mixtures. The formulations were comprised of ELO, Pripol 1009 and DMAP (0.5\% of total weight) with native, gelatinised or retrograded starch. Nonreversible heat flow traces of the formulations with the three starch types showed two overlapping exothermic transitions between $75{ }^{\circ} \mathrm{C}$ and $200{ }^{\circ} \mathrm{C}$, whilst the formulation without starch gave only one transition in that region (Fig. 7A).

It was also noted that the transition maximum onset occurred at a higher temperature (Table 2) and were broadened when starch was included in the formulation, suggesting initial retardation of the process and then extension of the curing interval. The shift of the onset of curing of the starch-free sample $\left(92.6{ }^{\circ} \mathrm{C}\right)$, i.e. the first transition to the sample containing HAS within the formulation was approximately $8{ }^{\circ} \mathrm{C}$ $\left(101.0{ }^{\circ} \mathrm{C}\right.$ ), whilst those for GS and RS formulations increased further to $104.1{ }^{\circ} \mathrm{C}$ and $107.8{ }^{\circ} \mathrm{C}$, respectively. The delay in cure may be due to slow diffusion of the molecules in the formulation as a result of starch inclusion.

The second transitions occurred at higher temperatures at around $150{ }^{\circ} \mathrm{C}$. These were slightly higher than that of the formulation without starch $\left(133.4{ }^{\circ} \mathrm{C}\right)$. The same trend was observed for the onset temperatures. The inclusion of starch in the formulation decreased the glass transition temperatures $\left(T_{\mathrm{g}}\right)$ of the cured products, in particular that containing HAS, which is in contrast to numerous studies reporting an increase 


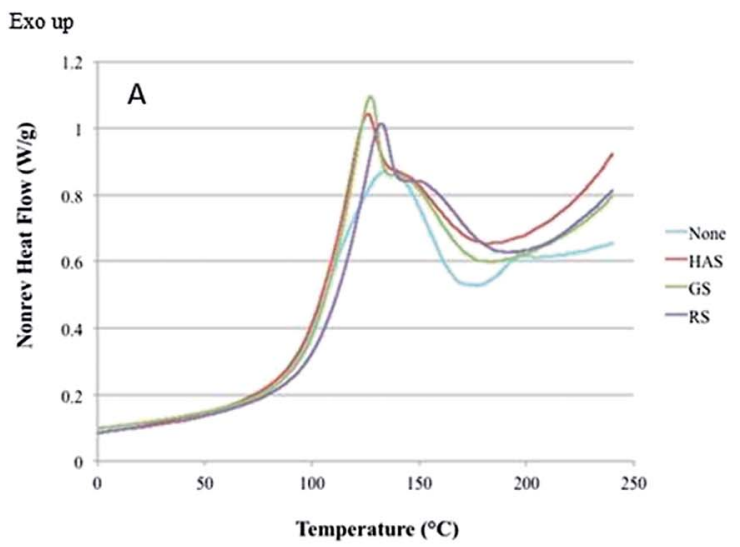

Exo up

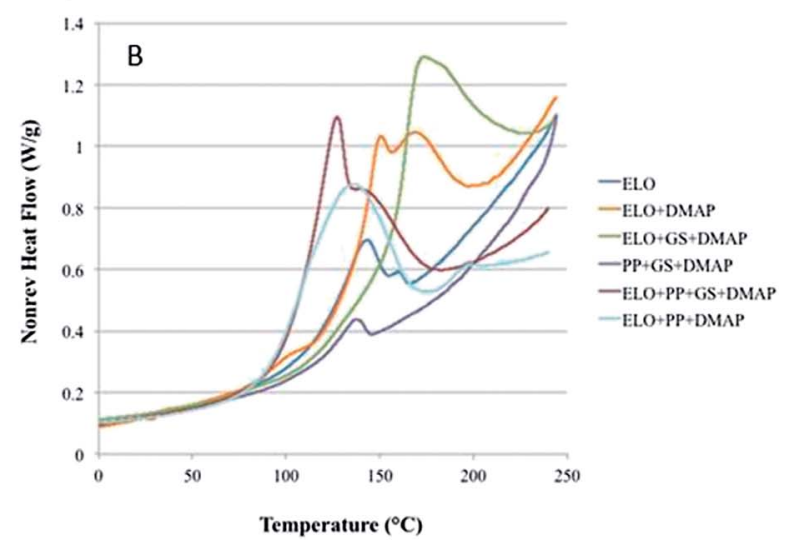

Fig. 7 (A) DSC thermograms of formulations comprised of ELO, Pripol, DMAP and different types of starch - native high amylose corn starch (HAS), gelatinised starch (GS) and retrograded starch (RS) and (B) DSC thermograms of various formulations (1) ELO, (2) ELO and DMAP, (3) ELO, GS and DMAP, (4) Pripol, GS and DMAP, (5) ELO, Pripol, GS and DMAP and (6) ELO, Pripol and DMAP.

in $T_{\mathrm{g}}$ possibly due to enhanced hydrogen bonding between starch particles and in some occasions, between the filler and the polymer matrix. ${ }^{48-50}$ However, the fall-off of the $T_{\mathrm{g}}$ has also been observed, and was believed to be due to the poor interaction of the polymer with the filler particles, which was likely to be the case with some of the components of these ELO based resins with starch filler. ${ }^{51}$ The total heat of cure increased moderately in the presence of the starch, with the total heat of reaction typically related to degree of cure of the polymer. ${ }^{14,52} \mathrm{~A}$ similar observation was made by Wu et al. in their calorimetric study of the effect of carbon fillers on the curing of epoxy resin. ${ }^{53}$ According to the study of the model systems mentioned

Table 2 Summary of MDSC results of starch formulations

\begin{tabular}{lllll}
\hline $\begin{array}{l}\text { Starch } \\
\text { type }\end{array}$ & $\begin{array}{l}\text { Total heat of } \\
\text { reaction }\left(\mathrm{J} \mathrm{g}^{-1}\right)\end{array}$ & $\begin{array}{l}\text { Onset } \\
\text { temperature }\left({ }^{\circ} \mathrm{C}\right)\end{array}$ & $\begin{array}{l}\text { Peak } \\
\text { temperature }\left({ }^{\circ} \mathrm{C}\right)\end{array}$ & $T_{\mathrm{g}}\left({ }^{\circ} \mathrm{C}\right)$ \\
\hline None & 131.9 & 92.6 & 133.4 & -13.3 \\
HAS & 156.7 & 101.0 & 125.6 & -29.6 \\
GS & 156.6 & 104.1 & 127.4 & -19.3 \\
RS & 162.6 & 107.8 & 132.0 & -17.2
\end{tabular}

previously, the transition observed in the formation with ELO, Pripol and DMAP ostensibly corresponds to the esterification reaction of the epoxide and carboxylic acid. Regarding the starch included formulations, further study is needed in order to explain the two overlapping transitions observed. Therefore the following compositions were analysed:

1. ELO;

2. ELO and DMAP;

3. ELO, gelatinised starch (GS) and DMAP;

4. Pripol 1009 (PP), gelatinised starch (GS) and DMAP.

The resulting MDSC traces of these formulations and the previously studied ELO + PP + GS + DMAP and ELO + PP + DMAP formulations were overlaid, and are shown in Fig. 7B with the results presented in Table 3 .

The thermogram from neat ELO had an exothermic transition with two visible peaks at $142.2{ }^{\circ} \mathrm{C}$ and $159.8{ }^{\circ} \mathrm{C}$. The first peak was likely to correspond to the ring opening of the oxirane rings and the smaller peak at higher temperature was attributed to the possible subsequent etherification reaction. ${ }^{37}$ By adding DMAP to ELO, both transitions could still be seen but occurred at slightly higher temperatures, however, the heat of reaction increased significantly. This suggests that DMAP promotes a greater degree of curing in the system. We attempted to monitor homopolymerisation of epoxy resin using DMAP as catalyst via ${ }^{1} \mathrm{H}$ and ${ }^{13} \mathrm{C}$ solution NMR but with limited success as no obvious changes were observed in the spectra even after $6 \mathrm{~h}$ heating at $140{ }^{\circ} \mathrm{C}$. The addition of starch (gelatinised) in the mixture of ELO and DMAP appears to delay the curing reaction by increasing the maximum exothermic heat flow temperature to $172.1{ }^{\circ} \mathrm{C}$. However, the total enthalpy of reaction moderately increased, suggesting that some additional curing may be occurring in the presence of the starch filler. This is in good agreement with the thermal decomposition results that also suggested that some possible additional crosslinking had occurred in the presence of starch. By analogy to hemp fibre and epoxidised oil, Boquillon et al. reported that the change in the cure mechanism was due to hydroxyl group presence of the vegetable fibre. ${ }^{19}$ In our case, the increase of total enthalpy of reaction in the presence of starch may also possibly be explained by the hydroxyl groups in starch, which could facilitate the ring-opening of epoxide rings, and hence, promote polymerisation but this only a conjecture at present as solidstate NMR proved to be inconclusive.

The formulation comprising Pripol 1009, starch and DMAP also showed an exothermic peak at $136.1^{\circ} \mathrm{C}$. However, the total heat of reaction of this formulation was relatively low, suggesting minimal reaction had occurred between the two components in the presence of DMAP. According to these experiments, the two exothermic transitions observed in the formulation of ELO, Pripol 1009, starch and DMAP were presumably due to heterogeneity of the mixture. The first transition corresponded to the reaction of ELO and Pripol 1009 in the vicinity where less starch was present. Whereas the region where more starch was present, the steric hindrance caused by the starch granules slowed down the reaction between ELO and Pripol, resulting in a higher maximum exothermic heat flow temperature. The glass transitions $\left(T_{\mathrm{g}}\right)$ of these cured products 
Table 3 MDSC results of various formulations (1) ELO, (2) ELO and DMAP, (3) ELO, GS and DMAP, (4) Pripol, GS and DMAP

\begin{tabular}{lccc}
\hline Formulation & Total heat of reaction $\left(\mathrm{J} \mathrm{g}^{-1}\right)$ & Onset temperature $\left({ }^{\circ} \mathrm{C}\right)$ & Peak temperature $(\mathrm{s})\left({ }^{\circ} \mathrm{C}\right)$ \\
\hline ELO & 37.0 & 119.3 & $142.2,159.8$ \\
ELO + DMAP & 110.1 & 136.3 & $150.8,169.0$ \\
ELO + GS + DMAP & 148.9 & 156.0 & 172.1 \\
PP + GS + DMAP & 7.1 & 120.5 & 136.1
\end{tabular}

were recorded to yield further information about the extent of crosslinking. Dell'Erba et al. have reported that thermosets prepared with DMAP as catalyst had a considerably higher $T_{\mathrm{g}}$ than those made using conventional tertiary amine catalysts, ${ }^{37}$ ascribing the difference to a higher resin crosslink density. From Table 3 it can be seen that heating pure ELO and ELO with the DMAP catalyst led to similar $T_{\mathrm{g}}$ 's and hence the regions that were crosslinked were of a similar crosslink density. The addition of GS to the ELO-DMAP mixture after curing increased the final products $T_{\mathrm{g}}$ significantly to $-18{ }^{\circ} \mathrm{C}$ suggesting good initial miscibility with ELO and GS, with the GS restricting chain mobility. The reaction of ELO and Pripol with catalyst led to higher enthalpies of reaction and a product with a final higher $T_{\mathrm{g}}$ leading to the conclusion that the amount and final crosslink density was even higher. The addition of the different starch types to this composition decreased the final product $T_{\mathrm{g}}$ (Table 2). It is likely that this is due to partial phase separation of the Pripol and ELO, and the subsequent higher ratio of ELO-ELO reaction. The change in structure of the granular HAS to GS and RS expanded porous structures with higher surface area can be seen to make a real impact on the final products $T_{\mathrm{g}}$. The expanded starches GS and RS with good surface areas also have good macroporous and mesoporous structures. ${ }^{54}$ This will allow much better interpenetration of the polymers within, and hence, higher probability of a reaction between the starch and ELO, greater accessibility of the Pripol and final limitation of cured polymer chain freedom. This can be seen initially from the low surface area HAS, where granule separation within the matrix was evidenced by SEM (see Fig. 3 and 4) resulting in a significantly reduced $T_{\mathrm{g}}$. The increased surface area of the GS and $\mathrm{RS}$ resulted in final material $T_{\mathrm{g}}$ 's approaching that of the Pripol-ELO mixture. ${ }^{55}$

\section{Viscosity study}

A viscosity study of the formulations consisting of ELO, Pripol and DMAP with different types of starch (native, gelatinised and retrograded) was conducted in order to follow the progress of polymerisation, and determine the gel point of these reaction mixtures. The steady shear rate was applied to all samples, which were cured at $140{ }^{\circ} \mathrm{C}$. The rise of viscosity was noted at the beginning of the observation when starch was included in the formulation, in particular gelatinised and retrograded starches (Fig. 8A).

The initial viscosity slightly increased from $2000-3000 \mathrm{cP}$ in the neat mixture to $4000-5000 \mathrm{cP}$ for the unmodified starch mixture. The mixtures with modified starch showed even higher initial viscosities of 12 000-18 $000 \mathrm{cP}$. The augmentation in viscosity for formulations with filler was expected as the suspended particles perturb the flow of the material, resulting in an increase of dissipated energy and resultant viscosity increase. ${ }^{56}$

The gel point of the formulation without starch was determined at approximately 700 seconds of heating. The addition of starch clearly hindered the gel point as these mixtures gelled after 1200 seconds of heating. This was in accordance with the thermal analysis data, which revealed that the presence of starch delayed the polymerisation/cure reaction.

To investigate the effect of starch concentration on viscosity and cure increase, different amounts of gelatinised starch were included into the standard formulation and the development of the viscosity at $140{ }^{\circ} \mathrm{C}$ with steady shear rate was pursued. As anticipated, the gel time of the reaction mixture increased in
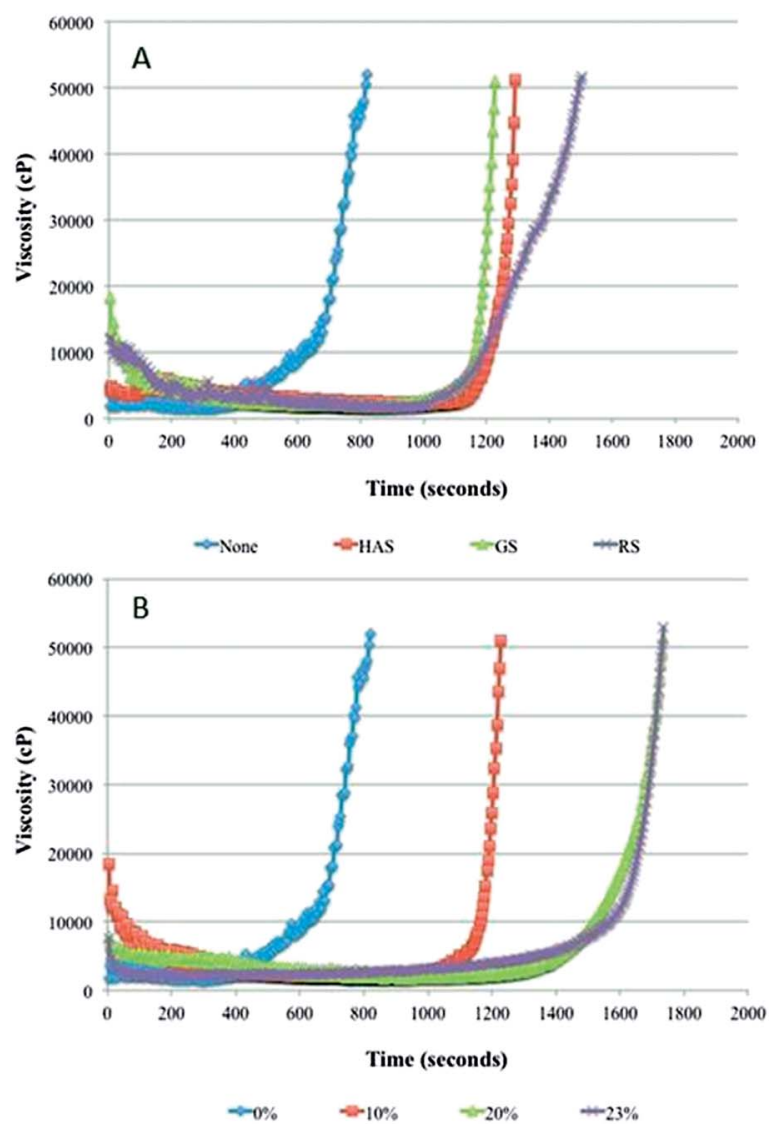

Fig. 8 (A) Viscosity of reaction mixtures of ELO, Pripol and DMAP with (1) no starch, (2) unmodified starch (HAS), (3) gelatinised (GS) and (4) retrograded starch (RS) and (B) viscosity of reaction mixture of ELO, Pripol and DMAP with different amounts of gelatinised starch. 
correlation with the amount of starch included in the formulation (Fig. 8B). The neat mixture started to gel at around 700 seconds. By incorporating $10 \mathrm{wt} \%$ of starch in the mixture, the gel time rose to near 1200 seconds. When the starch-loadings increased to $20 \mathrm{wt} \%$ and $23 \mathrm{wt} \%$, the gel points increased further to around 1500-1600 seconds, which doubled the gelling time of formulation without starch ( $\approx 700$ seconds). This suggests that the reaction mixture is effectively interacting with the expanded porous starches. It is also noted that starch and in particular porous starches are poor thermal conductors which could also limit to some extent the onset of the reaction under these condition of reaction.

\section{Curing study by infrared spectroscopy}

As NMR proved troublesome in trying to elucidate a possible mechanism, an infrared spectroscopic study was undertaken. The mixtures of two components were conducted in order to facilitate the interpretation of spectra. The IR study of the mixture of ELO and Pripol in the presence of DMAP catalyst was described in a previous report. ${ }^{16}$ In this section, the IR study of a mixture of expanded starch and ELO, and a second formulation of expanded starch and Pripol, both of which contained DMAP, were heated to $140{ }^{\circ} \mathrm{C}$, and samples were taken every 30 minutes. For mixtures of ELO and expanded starch in the presence of DMAP the IR spectra were recorded at 0, 30, 60 and 90 minutes (ESI, Fig. S8 $\dagger$ ). At the onset of the observation ( $0 \mathrm{~min}$ ), traces of toluene were observed. These bands disappeared after 30 minutes, indicating the evaporation of the solvent. The characteristic band of the hydroxyl group in starch was observed at $3323 \mathrm{~cm}^{-1}$ in dried expanded starch. When starch was suspended in toluene, this band slightly shifted to $3333 \mathrm{~cm}^{-1}$. ELO and Pripol showed no bands in this area (ESI, Fig. S9-S12 $\dagger$ ). At the onset of the observation, a broad band at $3433 \mathrm{~cm}^{-1}$ could be clearly seen in the spectrum of this reaction mixture (ESI, Fig. S8 $\dagger$ ). This shift might arise from the possible change in the hydrogen bonding network of the starch hydroxyl groups in the presence of the epoxide groups of the ELO, and assist with the ring-opening reaction. Alcohol assisted ringopening reactions of epoxides are well known. ${ }^{57,58}$ This postulation was in agreement with the result from the thermal analysis, which revealed that the higher enthalpy of curing was obtained with the mixture containing starch. At 30 minutes, a low-intensity band was observed at $3456 \mathrm{~cm}^{-1}$, which shifted overtime to 3464 and $3476 \mathrm{~cm}^{-1}$ after 60 and 90 minutes, respectively. The band was likely due to the end-chain hydroxyl group from homopolymerisation of ELO (ESI, Fig. S13 $\dagger$ ). Furthermore, a band at $1742 \mathrm{~cm}^{-1}$, corresponding to the $\mathrm{C}=\mathrm{O}$ ester group in the triglyceride was noted at the beginning of the observation. A minimal shift $\left(1740 \mathrm{~cm}^{-1}\right)$ was perceived after 90 minutes of curing. This was also observed in the homopolymerisation of ELO in the presence of DMAP. Zhang et al. studied a preparation of a composite comprised of polyester and solid epoxy and also observed a slight change in their IR spectra regarding the original PLA ester band, compared to the new ester band of the composite. ${ }^{59}$ Similar observation could be made at the beginning of the experiments for mixtures of
Pripol, expanded starch and DMAP (ESI, Fig. S14†). Bands from toluene were noted at the beginning, disappearing after 30 minutes of heating, due to solvent evaporation. The stretching of hydroxyl in starch was also detected at around $3400 \mathrm{~cm}^{-1}$ at the onset of the reaction. After 30 minutes, there was no evident change in the spectra until the end of the observation. In conclusion, IR data suggested that starch present in the formulation could possibly facilitate the ring opening of the epoxides, as a consequence leading to a greater heat of reaction and improved interaction, as previously evidenced by the DSC, TGA and mechanical studies respectively.

\section{Conclusions}

The use of porous, high surface area gelatinised and retrograded high amylose corn starch as filler in ELO composites considerably improved the mechanical properties of these films. The optimum formulation was achieved when $20 \mathrm{wt} \%$ of gelatinised starch was present in the mixture. This formulation yielded a film with $227 \%$ improvement in tensile strength and $166 \%$ enhancement in Young's modulus, compared to those with no added starch. The optimum curing temperature of these films was $140{ }^{\circ} \mathrm{C}$, at which the highest tensile strength and lowest colouration were obtained. SEM micrographs showed uniform dispersion of gelatinised and retrograded starch granules in the polymer matrix, whilst the cross-section of films with native starch showed phase separation. This was potentially attributed to greater monomer penetration into the porous structure of modified starch and surface roughness, leading to better dispersion. The porous structure led to greater coverage of the polymer, resulting in lower water uptake compared to that of native starch films. A higher heat of reaction was obtained when starch was present in the formulation, possibly indicating a greater degree of crosslinking, resulting in improved mechanical properties of the starch films. This was in good agreement with the decomposition study of starch films, which confirmed that a part of the material had a greater degree of crosslinking. Infrared spectra showed that starch might aid the curing process via promotion of oxirane ring-opening. Such films may find use as bio-based alternatives to vinyl films in a wide range of applications.

\section{Acknowledgements}

The authors would like to thank members of the Green Chemistry Centre of Excellence for their input and useful discussions. N.S. would like to thank the Thai government for her PhD research funding. Croda is duly acknowledged for their kind supply of Pripol 1009. P. S. gratefully acknowledges the Ministerio de Ciencia e Innovación for the concession of a Juan de la Cierva (JCI-2011-10836) contract.

\section{Notes and references}

1 J. C. Ronda, G. Lligadas, M. Galià and V. Cádiz, Eur. J. Lipid Sci. Technol., 2011, 113, 46-58. 
2 J. D. J. van den Berg, N. D. Vermist, L. Carlyle, M. Holčapek and J. J. Boon, J. Sep. Sci., 2004, 27, 181-199.

3 M. A. R. Meier, J. O. Metzger and U. S. Schubert, Chem. Soc. Rev., 2007, 36, 1788-1802.

4 J. Mallégol, J. Lemaire and J.-L. Gardette, Prog. Org. Coat., 2000, 39, 107-113.

5 C. Stenberg, M. Svensson and M. Johansson, Ind. Crops Prod., 2005, 21, 263-272.

6 J. T. P. Derksen, F. Petrus Cuperus and P. Kolster, Prog. Org. Coat., 1996, 27, 45-53.

7 J. Powell, Linoleum, Gibbs Smith Publisher, Layton, 2003, p. 22.

8 Z. S. Petrović, Polym. Rev., 2008, 48, 109-155.

9 S. N. Khot, J. J. Lascala, E. Can, S. S. Morye, G. I. Williams, G. R. Palmese, S. H. Kusefoglu and R. P. Wool, J. Appl. Polym. Sci., 2001, 82, 703-723.

10 L. Hojabri, X. Kong and S. S. Narine, Biomacromolecules, 2009, 10, 884-891.

11 J. M. Raquez, M. Deléglise, M. F. Lacrampe and P. Krawczak, Prog. Polym. Sci., 2010, 35, 487-509.

12 N. Boquillon and C. Fringant, Polymer, 2000, 41, 8603-8613. 13 A. E. Gerbase, C. L. Petzhold and A. O. Costa, J. Am. Oil Chem. Soc., 2002, 79, 797-802.

14 S. Tan and W. Chow, J. Am. Oil Chem. Soc., 2011, 88, 915-923. 15 J. Rösch and R. Mülhaupt, Polym. Bull., 1993, 31, 679-685.

16 N. Supanchaiyamat, P. S. Shuttleworth, A. J. Hunt, J. H. Clark and A. S. Matharu, Green Chem., 2012, 14, 1759-1765.

17 A. O'Donnell, M. A. Dweib and R. P. Wool, Compos. Sci. Technol., 2004, 64, 1135-1145.

18 Z. Liu, S. Z. Erhan, D. E. Akin and F. E. Barton, J. Agric. Food Chem., 2006, 54, 2134-2137.

19 N. Boquillon, J. Appl. Polym. Sci., 2006, 101, 4037-4043.

20 S. Devereux, P. S. Shuttleworth, D. J. Macquarrie and F. Paradisi, J. Polym. Environ., 2011, 19, 971-979.

21 G. J. L. Griffin, in Fillers and Reinforcements for Plastics, ed. R. D. Deanin and N. R. Schott, American Chemical Society, 1974, vol. 134, pp. 159-170.

22 N. St-Pierre, B. D. Favis, B. A. Ramsay, J. A. Ramsay and H. Verhoogt, Polymer, 1997, 38, 647-655.

23 L. Mao, S. Imam, S. Gordon, P. Cinelli and E. Chiellini, J. Polym. Environ., 2000, 8, 205-211.

24 L. Averous, L. Moro, P. Dole and C. Fringant, Polymer, 2000, 41, 4157-4167.

25 M. F. Koenig and S. J. Huang, Polymer, 1995, 36, 1877-1882.

26 P. S. Shuttleworth, J. H. Clark, R. Mantle and N. Stansfield, Green Chem., 2010, 12, 798-803.

27 S. Brunauer, P. H. Emmett and E. Teller, J. Am. Chem. Soc., 1938, 60, 309-319.

28 H. H. Winter and F. Chambon, J. Rheol., 1986, 30, 367-382. 29 S. Mortimer, A. J. Ryan and J. L. Stanford, Macromolecules, 2001, 34, 2973-2980.

30 S. Doi, J. H. Clark, D. J. Macquarrie and K. Milkowski, Chem. Commun., 2002, 2632-2633.
31 P. S. Shuttleworth, V. Budarin and J. H. Clark, J. Mater. Chem., 2009, 19, 8589-8593.

32 P. Shuttleworth, V. Budarin and J. Clark, J. Therm. Anal. Calorim., 2011, 105, 577-581.

33 S. Jeong, S. Yeo and S. Yi, J. Mater. Sci., 2005, 40, 5407-5411.

34 M. N. Ichazo, C. Albano, J. González, R. Perera and

M. V. Candal, Compos. Struct., 2001, 54, 207-214.

35 D. Bikiaris, J. Prinos, K. Koutsopoulos, N. Vouroutzis,

E. Pavlidou, N. Frangis and C. Panayiotou, Polym. Degrad. Stab., 1998, 59, 287-291.

36 L. Hill and S.-B. Lee, J. Coat. Technol., 1999, 71, 127-133.

37 I. E. Dell'Erba and R. J. J. Williams, Polym. Eng. Sci., 2006, 46, 351-359.

38 M. Tajvidi and G. Ebrahimi, J. Appl. Polym. Sci., 2003, 88, 941-946.

39 C. Fringant, J. Desbrières and M. Rinaudo, Polymer, 1996, 37, 2663-2673.

40 L. Shechter and J. Wynstra, Ind. Eng. Chem., 1956, 48, 86-93. 41 L. Matějka, S. Pokomý and K. Dušek, Polym. Bull., 1982, 7, 123-128.

42 P.-J. Madec and E. Maréchal, Analysis/Reactions/Morphology, Springer, Berlin, 1985, pp. 153-228.

43 P.-J. Madec and E. Maréchal, Makromol. Chem., 1983, 184, 343-355.

44 P.-J. Madec and E. Maréchal, Makromol. Chem., 1983, 184, 357-369.

45 I. E. Dell'Erba and R. J. J. Williams, Polym. Eng. Sci., 2006, 46, 351-359.

46 I. E. dell'Erba and R. J. J. Williams, Eur. Polym. J., 2007, 43, 2759-2767.

47 Y. Li, Y. Fan and J. Ma, Polym. Degrad. Stab., 2001, 73, 163167.

48 X. C. Ge, X. H. Li, Q. Zhu, L. Li and Y. Z. Meng, Polym. Eng. Sci., 2004, 44, 2134-2140.

49 S. Peng, X. Wang and L. Dong, Polym. Compos., 2005, 26, 3741.

50 E. Kristo and C. G. Biliaderis, Carbohydr. Polym., 2007, 68, 146-158.

51 B. J. Ash, L. S. Schadler and R. W. Siegel, Mater. Lett., 2002, 55, 83-87.

52 X. Kornmann, H. Lindberg and L. A. Berglund, Polymer, 2001, 42, 4493-4499.

53 J. Wu and D. D. L. Chung, Carbon, 2004, 42, 3039-3042.

54 P. S. Shuttleworth, V. Budarin, R. J. White, V. M. Gun'ko, R. Luque and J. H. Clark, Chem.-Eur. J., 2013, 19, 9351-9357. 55 S. H. Kim, I.-J. Chin and J.-S. Yoon, Korea Polym. J., 1998, 6, 422-427.

56 E. Guth, J. Appl. Phys., 1945, 16, 20-25.

57 K. Fagnou and M. Lautens, Org. Lett., 2000, 2, 2319-2321.

58 A. Berkessel, E. Ashkenazi and M. R. M. Andreae, Appl. Catal., A, 2003, 254, 27-34.

59 J. Zhang, G. Li, Y. Su, R. Qi, D. Ye, J. Yu and S. Huang, J. Appl. Polym. Sci., 2012, 123, 2996-3006. 